\title{
Dimensional analysis of the coping strategy indicator in a sample of elderly veterans with acquired limb amputations
}

\author{
Deirdre M. Desmond ${ }^{\mathrm{a}, 1}$, Mark Shevlin ${ }^{\mathrm{b}}$, Malcolm MacLachlan ${ }^{\mathrm{c}, *, 1}$ \\ a Department of Psychology, National University of Ireland, Maynooth, Co. Kildare, Ireland \\ ${ }^{\mathrm{b}}$ School of Psychology, University of Ulster at Magee College, Northern Ireland \\ ' School of Psychology, University of Dublin, Trinity College, Dublin, Ireland
}

Received 3 August 2004; accepted 26 April 2005

Available online 6 October 2005

\begin{abstract}
The Coping Strategy Indicator (CSI), developed by Amirkhan (1990), is intended as a 'widely applicable' self-report measure of situational coping encompassing the strategies of avoidance, problem solving and seeking social support. Nonetheless, the instrument's initial development phase was exclusively premised on Californian samples, prompting Parker and Endler (1992) to highlight the need for cross-validation with other populations. The aim of this study was to examine the factor structure of the Coping Strategy Indicator in a sample of 618 British individuals with a chronic health challenge, namely amputation of a limb(s). Confirmatory factor analyses were used to compare four different models of the CSI structure (one-factor, three-orthogonal factors, three-oblique factors and four-oblique factors). The results indicate that the oblique-three-factor model, coherent with the subscales derived in the original sample (Amirkhan, 1990) provided adequate fit to the data. An oblique four-factor model described by Ager and MacLachlan (1998) provided the best fit. Further research is necessary in terms of developing and scoring the instrument as a four-dimensional tool. These results provide further support for the suggestion that the scale is generalizable across population, cultural, and situational variation.
\end{abstract}

(C) 2005 Published by Elsevier Ltd.

\footnotetext{
* Corresponding author. Address: School of Psychology, Dublin Psychoprosthetics Group, Trinity College, University of Dublin, Dublin 2, Ireland. Tel.: +353 1608 1453; fax: +353 16712006.

E-mail address: malcolm.maclachlan@tcd.ie (M. MacLachlan).

${ }^{1}$ Dublin Psychoprosthetics Group, www.tcd.ie/psychoprosthetics.
} 
Keywords: Amputation; Coping Strategy Indicator; Confirmatory factor analysis; Psychometrics

\section{Introduction}

Although there is no universally accepted definition of coping it has broadly been defined as "cognitive and behavioural efforts to manage specific external or internal demands (and conflicts between them) that are appraised as taxing the resources of a person" (Lazarus, 1991, p.112). The various coping strategies individuals adopt to cope with stressful life experiences play critical mediating roles in adaptation to stressful situations (Endler, Corace, Summerfeldt, Johnson, \& Rothbart, 2003; Livneh, Antonak, \& Gerhardt, 1999, 2000). The dimensionality of coping responses has stimulated substantial theoretical and empirical enquiry (Mikulincer \& Florian, 1996; Schwarzer \& Schwarzer, 1996). A classic bipartite classification proposed by Lazarus and Folkman (1984) discriminates between problem-focused and emotion focused coping. The former is problem centred in that the person-environment relationship is altered by instrumental actions. The latter is mainly comprised of cognitive coping strategies that do not directly change the situation but rather allow new meaning to be assigned, thereby regulating the emotions associated with the stressful event (Folkman \& Lazaru's, 1985, 1980; Lazarus \& Folkman, 1984).

Largely predicated on Folkman and Lazaru's $(1985,1980)$ classic work, a burgeoning literature has sought to investigate the basic coping strategies utilised in response to stressful circumstances and to develop standardised coping assessments (e.g. Amirkhan, 1990; Billings \& Moos, 1984; Carver, Scheier, \& Kumari Weintraub, 1989; Endler \& Parker, 1990). One of these measures, the Coping Strategy Indicator (Amirkhan, 1990) is distinguished by the combination of both inductive and deductive methodologies characterising its development. Criticism of purely deductive approaches centres largely on lack of empirical support whereas exclusively inductive approaches are limited in terms of generalisability and their contributions to our conceptual understanding of coping processes (Amirkhan, 1990; Haan, 1982; Parker \& Endler, 1992).

Through progressive refinement of a coping strategy item pool across multiple samples and a heterogeneous range of stressors, Amirkhan (1990) sought to inductively derive an instrument which had significant generalisability across populations (Ager \& MacLachlan, 1998). The resulting assessment, the CSI, is a thirty-three item self-report questionnaire, measuring the use of three coping strategies (namely Problem Solving, Seeking Social Support, and Avoidance) in response to a specific stressor. Although not exhaustive of possible coping strategies this tripartite structure is appealing as it corresponds to the most basic human reactions to threat (Amirkhan, 1990). Problem Solving, a direct assault strategy, is derivative of primitive "flight"” tendencies, and involves an instrumental, problem-oriented approach to active management of stressors. Seeking Social Support relates to the basic human need for human contact in times of duress and is manifest through a process of actively turning to others for comfort, help and advice. Finally, Avoidance comprising escape responses seems derivative of "flight" tendencies involving physical and/ or psychological withdrawal, for example, through distraction or fantasy. The CSI has been used 
with a wide variety of populations to assess coping strategies in a variety of contexts. For example, undergraduate students, exam-related coping and responses to racial discrimination (Ptacek, Smith, Espe, \& Raffety, 1994; Utsey, Ponterotto, Reynolds, \& Cancelli, 2000), coping responses of spouses of depressed patients (Spangenberg \& Theron, 1999), returning refugees (Gillespie, Peltzer, \& MacLachlan, 2000), haemodialysis patients (Welch \& Austin, 2001), psychiatric inpatients (Bijttebier \& Vertommen, 1999), international medical students (Glennon \& MacLachlan, 2000) and individuals with amputations (Gallagher \& MacLachlan, 1999).

During the development of the CSI the factor structure was cross-validated in a number of samples, however, each of these involved normal adults in a southern Californian community (Amirkhan, 1990). Hence, although Parker and Endler (1992) commend the psychometric robustness of the CSI compared to other coping assessments they also highlight the need for cross-validation with other populations. Replication of the three-factor structure was subsequently achieved in a Flemish general population sample (Bijttebier \& Vertommen, 1997) and in a sample of North American undergraduate students (Ptacek et al., 1994) using principal components analysis. Using confirmatory factor analysis, Clark, Bormann, Cropanzano, and James, 1995 also replicated the tri-factorial structure in a sample of predominantly female undergraduate students in the United States. However, investigation of the underlying factor structure of the CSI in a sample of Malawian undergraduate students led Ager and MacLachlan (1998) to propose a four-factor model involving the bipartition of the Avoidance factor. This division was also evident in the original validation studies; however, Amirkhan rejected the four-factor solution on the grounds that "the addition of a fourth-factor did not appreciably increase explained variance, and, in fact simply split the avoidance strategy into two highly correlated subsets" (Amirkhan, 1990, p. 1068). Despite conceptual misgivings Ager and MacLachlan (1998) also ultimately rejected this dichotomisation of Avoidance into Avoidance-Withdrawal and Avoidance-Distraction on the basis of inadequate psychometric support.

The current study aims to determine the replicability of the CSI structure, using confirmatory factor analysis, in a sample of British veterans who have undergone amputation of a limb(s). The predominately elderly sample and the chronic nature of the stressor, presenting both significant physical and psychological challenges, differs substantially from those represented in previous assessments of CSI validity (e.g. Ager \& MacLachlan, 1998; Clark et al., 1995) and thus provides a strong test of the robustness of the instrument.

\section{Method}

\subsection{Participants}

The CSI was completed by members of the British Limbless Ex-Service Men's Association (BLESMA) as part of a larger postal survey of psychosocial adaptation to amputation. BLESMA is a national charity dedicated to promotion of the welfare of those who have lost a limb or limbs, one or both eyes, or the use of a limb in any branch of Her Majesty's Forces or Auxiliary Forces. Almost three quarters of BLESMA's 2500 members have acquired amputations. Six hundred and eighteen individuals (18 females, 600 males; mean age 72.05 years, SD $=13.49$ ) completed all 
33-items of the CSI and are included in the current analyses. $84 \%(n=516)$ had an amputation of a lower $\operatorname{limb}(\mathrm{s})$, the average time since amputation was 42 years $(\mathrm{SD}=21.71)$.

\subsection{The coping strategy indicator}

Responses on each of the CSI's 33-items are indicated by means of a three point scale: a lot (3), a little (2), or not at all (1). The three subscales each contain 11 items and subscale scores are calculated by summing responses to appropriate items (range 0-33), higher scores indicate greater use of the strategy.

Cronbach's alpha coefficients indicate adequate internal consistency for each of the subscales ranging from 0.86 to 0.98 for Problem Solving, 0.89 to 0.98 for Seeking Social Support and from 0.77 to 0.96 for Avoidance (Amirkhan, 1990; Bijttebier \& Vertommen, 1997; Clark et al., 1995; Utsey et al., 2000).

In the original version of the scale respondents are asked to identify a stressful event occurring within the last 6 months and to consider the manner in which they had coped with it. In the current study 'coping with amputation' was specified as the event. Respondents were required to think of a problem encountered in relation to their injury in the past 6 months and reflect on their coping strategies.

\subsection{Confirmatory factor analysis and assessment of model fit}

A series of confirmatory factor analyses was conducted using LISREL 8.7 (Joreskog \& Sorbom, 2004). The models parameters were estimated using maximum likelihood with a covariance matrix and evaluated using the Satorra-Bentler scaled chi-square.

In keeping with common practice (e.g. Bollen \& Long, 1993; Hu \& Bentler, 1998) a number of fit indexes were examined in order to determine the adequacy of model fit: the Satorra-Bentler scaled chi-square (Satorra \& Bentler, 1988), the root-mean-square error of approximation (RMSEA) with $90 \%$ confidence intervals $(90 \% \mathrm{CI})$, the standardized root-mean residual (SRMR) and the Comparative Fit Index (CFI: Bentler, 1988). Perhaps the most well-known measure of overall model fit is the chi-square statistic which evaluates the significance of unexplained covariances, or covariances among measured variables that are not accounted for by the model (Stevens, 2002). In essence it examines departure of the data from the specified model, thus statistically nonsignificant values of chi-square indicate poor fit. However, it is recognised that 'trivial' variations in fit, particularly with large sample sizes can easily produce a significant and sizeable $\chi^{2}$ statistic (Bollen \& Long, 1993). The RMSEA is a measure of the discrepancy of fit, essentially a measure of lack of fit per degree of freedom (MacCallum, 1995). Hu and Bentler (1999) propose that RMSEA values of close to 0.06 are optimal while values up to 0.08 are acceptable. The SRMR is a standardised summary of the average covariance residuals. When the model fit is perfect SRMR is zero. Hu and Bentler (1999) suggest that an SRMR value of close to .08 is indicative of relatively good fit. The CFI is an incremental fit index. Models with CFI values close to 0.95 are viewed as fitting the data well (Hu \& Bentler, 1999), while values of close to .90 are generally accepted as adequate (Schumacker \& Lomax, 1996). The comparative fit of the models was assessed using the Expected Cross Validation Index (ECVI: Browne \& Cudeck, 1989), with the smallest value being indicative of the best fitting model. 


\subsection{Models tested}

We tested the goodness-of-fit for a single-factor model and orthogonal and oblique versions of the three-factor model proposed by Amirkhan (1990) (factor components are detailed in Table 1). Finally, Ager and MacLachlan (1998) four-factor formulation was evaluated. This involves splitting the Avoidance factor in two to form an Avoidance-withdrawal (items 13, 18, 21, 26, 30) and an Avoidance-distraction (items 10, 22, 27, 28) factor (note: two items, items 4 and 6, were

Table 1

Response proportions for the CSI items

\begin{tabular}{|c|c|c|c|}
\hline 1CSI item (subscale) & A lot & A little & Not at all \\
\hline 1. Described your feelings to a friend (SS) & 10.8 & 36.1 & 53.1 \\
\hline 2. Rearranged things so your problem could be solved (PS) & 39.0 & 32.2 & 28.8 \\
\hline 3. Thought of many ideas before deciding what to do (PS) & 41.4 & 28.3 & 30.3 \\
\hline 4. Tried to distract yourself from the problem (A) & 32.5 & 21.7 & 45.8 \\
\hline 5. Accepted sympathy and understanding from someone (SS) & 12.0 & 39.6 & 48.4 \\
\hline 6. Did all you could to keep others from seeing how bad things really were (A) & 41.3 & 24.9 & 33.8 \\
\hline $\begin{array}{l}\text { 7. Talked to people about the situation because talking about } \\
\text { it made you feel better (SS) }\end{array}$ & 9.7 & 35.6 & 54.7 \\
\hline 8. Set some goals for yourself to deal with the situation (PS) & 48.7 & 23.8 & 27.5 \\
\hline 9. Weighed up your options carefully (PS) & 47.9 & 26.4 & 25.7 \\
\hline 10. Daydreamed about better times (A) & 24.1 & 25.9 & 50.0 \\
\hline 11. Tried different ways to solve the problem until you found one that worked (PS) & 46.1 & 26.9 & 27.0 \\
\hline 12. Talked about fears and worries to a relative or friend (SS) & 8.3 & 31.6 & 60.2 \\
\hline 13. Spent more time than usual alone $(\mathrm{A})$ & 19.7 & 23.5 & 56.8 \\
\hline $\begin{array}{l}\text { 14. Told people about the situation because talking about } \\
\text { it helped you come up with solutions (SS) }\end{array}$ & 8.7 & 28.0 & 63.3 \\
\hline 15. Thought about what needs to be done to straighten things up (PS) & 37.4 & 33.5 & 29.1 \\
\hline 16. Turned your full attention to solving the problem (PS) & 48.1 & 27.3 & 24.6 \\
\hline 17. Formed a plan in your mind (PS) & 38.8 & 26.9 & 34.3 \\
\hline 18. Watched television more than usual (A) & 19.1 & 25.2 & 55.7 \\
\hline 19. Went to someone friend or professional to help you feel better (SS) & 7.4 & 18.8 & 73.8 \\
\hline 20. Stood firm and fought for what you wanted in the situation (PS) & 49.4 & 26.7 & 23.9 \\
\hline 21. Avoided being with people in general (A) & 7.0 & 21.5 & 71.5 \\
\hline 22. Buried yourself in a hobby or sports activity to avoid the problem (A) & 13.6 & 23.1 & 63.3 \\
\hline 23. Went to a friend to help you feel better about the problem (SS) & 3.1 & 15.5 & 81.4 \\
\hline 24. Went to a friend for advice about how to change the situation (SS) & 2.4 & 13.8 & 83.8 \\
\hline $\begin{array}{l}\text { 25. Accepted sympathy and understanding from friends who } \\
\text { had the same problem (SS) }\end{array}$ & 7.4 & 32.5 & 60.0 \\
\hline 26. Slept more than usual (A) & 7.6 & 27.7 & 64.7 \\
\hline 27. Fantasized about how things could have been different (A) & 21.0 & 27.8 & 51.1 \\
\hline 28. Identified with characters in movies or novels (A) & 2.3 & 7.8 & 90.0 \\
\hline 29. Tried to solve the problem (PS) & 47.9 & 24.9 & 27.2 \\
\hline 30. Wished that people would just leave you alone (A) & 12.6 & 27.7 & 59.7 \\
\hline 31. Accepted help from a friend or relative (SS) & 17.3 & 49.2 & 33.5 \\
\hline 32. Sought reassurance from those who know you best (SS) & 17.0 & 38.0 & 45.0 \\
\hline 33. Tried to carefully plan a course of action rather than acting on impulse (PS) & 37.1 & 30.9 & 32.0 \\
\hline
\end{tabular}

Original CSI subscales described by Amirkhan (1990): SS = Social Support, PS = Problem Solving, A = Avoidance. 
dropped from the model due to their failure to reach critical loading values in the exploratory phase of analysis).

Table 1 shows the response proportions for the 33 CSI items and details the components of each factor as described in Amirkhan (1990) original analysis.

\section{Results}

Table 2 reports the fit indices for the models tested. The Satorra-Bentler chi-square statistic was significant for all of the models $(p<.05)$ indicating that a significant proportion of the variance was unexplained by each model. However, this should not necessarily lead to model rejection, as 'trivial' variations in fit, particularly with large sample sizes can easily produce a significant and sizeable $\chi^{2}$ statistic (Bollen \& Long, 1993). On the basis of the RMSEA, SRMR, and the CFI the null model and the single-factor models were rejected as plausible models. The three-factor oblique model was a significantly better fit than the three-factor orthogonal model ( $\mathrm{S}-\mathrm{B} \chi^{2} \Delta=157$, df $\Delta=3, p<.05$; ECVI of 2.78 compared with 3.11). Furthermore, for the three-oblique factors model the values of SRMR, RMSEA and CFI were indicative of acceptable fit. A chi-square difference test or the use of the ECVI to compare the three-factor oblique model and the four-factor model was not possible as the models have different number of variables. However, the four-factor oblique model is a better fitting model in terms of the RMSEA, the SRMR and the CFI. The point estimate of the RMSEA for the four-factor oblique model (.053) is below the lower $90 \%$ confidence interval for the RMSEA for the oblique three-factor model. In addition, the chi-square/degrees of freedom ratio for the four-factor model (2.76) is less than that for the four-factor model (3.20). These factors suggest that the oblique four-factor model is the best explanation of the sample data.

Cronbach's alpha coefficients of .9220 and .8687 were obtained for the Problem Solving and Support Seeking scales, respectively. Internal reliabilities for the Avoidance-Withdrawal and Avoidance-Distraction scales were .74 and .63, respectively whereas the Cronbach's alpha coeffi-

Table 2

Goodness of fit indicators for the models tested

\begin{tabular}{|c|c|c|c|c|c|}
\hline Model & $\mathrm{S}-\mathrm{B} \chi^{2}(\mathrm{df})$ & RMSEA & SRMR & CFI & $\mathrm{ECVI}^{\mathrm{a}}$ \\
\hline Null model & $\begin{array}{l}24,374 \\
(528)\end{array}$ & $\begin{array}{l}.27 \\
(.27-.27)\end{array}$ & .27 & .04 & 39.61 \\
\hline Single factor model & $\begin{array}{l}6420 \\
(495)\end{array}$ & $\begin{array}{l}.14 \\
(.14-.14)\end{array}$ & .11 & .76 & 10.62 \\
\hline $\begin{array}{l}\text { Three-factor orthogonal model } \\
\text { (Amirkhan 1990) }\end{array}$ & $\begin{array}{l}1786 \\
(495)\end{array}$ & $\begin{array}{l}.065 \\
(.062-.068)\end{array}$ & .15 & .95 & 3.11 \\
\hline Three oblique factors & $\begin{array}{l}1578 \\
(492)\end{array}$ & $\begin{array}{l}.060 \\
(.057-.063)\end{array}$ & .059 & .96 & 2.78 \\
\hline $\begin{array}{l}\text { Four-factor model } \\
\qquad(\text { Ager \& MacLachlan, 1998) }\end{array}$ & $\begin{array}{l}1181 \\
(428)\end{array}$ & $\begin{array}{l}.053 \\
(.050-.057)\end{array}$ & .054 & .97 & 2.13 \\
\hline
\end{tabular}

\footnotetext{
${ }^{\text {a }}$ ECVI for saturated model $=1.82$.
} 
cient calculated for the full CSI Avoidance scale was .79. Thus the reliability analyses suggest that although the four-factor solution provides insight into different areas of avoidant strategies, subscales based on such a solution do not provide an appreciably more reliable account of coping behaviour in the current sample than those based on a three-factor solution.

Table 3

Factor loadings for the confirmatory factor analysis of the Coping Strategy Indicator (4 oblique factors model)

Item Support Problem Avoidance- Avoidance-

Seeking Solving Distraction Withdrawal

1. Described your feelings to a friend

.67

2. Rearranged things so your problem could be solved

3. Thought of many ideas before deciding what to do

4. Tried to distract yourself from the problem

5. Accepted sympathy and understanding from someone

6. Did all you could to keep others from seeing how bad things really were

7. Talked to people about the situation because talking about it made you feel better

8. Set some goals for yourself to deal with the situation

9. Weighed up your options carefully

.71

.78

10. Daydreamed about better times

11. Tried different ways to solve the problem until you found one that worked

12. Talked about fears and worries to a relative or friend

13. Spent more time than usual alone

14. Told people about the situation because talking about it helped you come up with solutions

15. Thought about what need to be done to straighten things up

16. Turned your full attention to solving the problem

17. Formed a plan in your mind

18. Watched television more than usual

19. Went to someone friend or professional to help you feel better

20. Stood firm and fought for what you wanted in the situation

21. Avoided being with people in general

22. Buried yourself in a hobby or sports activity to avoid the problem

23. Went to a friend to help you feel better about the problem $\quad .68$

24. Went to a friend for advice about how to change the situation $\quad .58$

25. Accepted sympathy and understanding from friends who had the same problem

26. Slept more than usual

.43

27. Fantasized about how things could have been different

28. Identified with characters in movies or novels

29. Tried to solve the problem

30. Wished that people would just leave you alone

31. Accepted help from a friend or relative

32. Sought reassurance from those who know you best

33. Tried to carefully plan a course of action rather than acting on impulse

Note: Items 4 and 6 were not included in the model. 
Table 4

Correlations between CSI factors

\begin{tabular}{llll}
\hline & Seeking Support & Problem Solving & Avoidance-Withdrawal \\
\hline 1. Seeking Support & & & \\
2. Problem Solving & .49 & & \\
3. Avoidance-Withdrawal & .27 & .26 & .63 \\
4. Avoidance-Distraction & .37 & .30 & .6 \\
\hline
\end{tabular}

All correlations were significant, $p<.05$.

The factor loadings for the four oblique factor model are presented in Table 3. All loadings were positive and statistically significant $(p<.05)$. Correlations between the factors are shown in Table 4.

\section{Discussion}

This study examined the factor structure of the CSI in a sample of veterans with chronic physical health challenge, limb amputations, thus allowing us to investigate the generalisability of the CSI factor structure. The sample and indeed the stressor differed substantially from those represented in previous assessments of CSI validity (e.g. Ager \& MacLachlan, 1998; Clark et al., 1995). A three-factor oblique model coherent with the subscales derived in the original validation samples (Amirkhan, 1990) provided adequate fit providing some support for the wide applicability and robustness of the CSI as a measure of situational coping. The coherence of the subscales is notable in light of difficulties in identifying replicable sets of coping dimensions in different populations using other coping scales (e.g. Lyne \& Roger, 2000; Parker \& Endler, 1992).

The best fitting model was an oblique four-factor model corresponding to Ager and MacLachlan (1998) formulation. The factor loadings for the CSI items indicate that they are relatively good indicators of their respective factors: the loadings on the Problem Solving factor range from .55 to .80 , loadings on the Seeking Social Support factor range from .43 to .73 and loadings on the Avoidance-Withdrawal factor range from .48 to .72. The loadings on the Avoidance-Distraction factor range from .31 to .80 and although somewhat lower are still adequate indicators.

It is notable that this four-dimensional pattern was also evidenced in the original scale development phase but was rejected on the grounds of parsimony (Amirkhan, 1990). Ptacek et al. (1994) expressed reservations about the content of the CSI Avoidance subscale suggesting that it incorporates greater diversity in terms of forms of Avoidance including, for example, day dreaming, behavioural avoidance and denial, than is evident in the Problem Solving and Seeking Support scales. Their analysis revealed that split-half reliability for the Avoidance scale (.52) was appreciably lower than for either the Problem Solving or Seeking Social Support scales (.76 and .84 , respectively). Further research is warranted either in terms of developing the scale as a fourdimensional assessment or refining the content of the Avoidance subscale.

In contrast to previous research (Ager \& MacLachlan, 1998; Amirkhan, 1990) the oblique three-factor solution resulted in a significant improvement in fit over the orthogonal solution. The correlations between the factors indicate that they share a significant but relatively low degree of variation (range 14-24\%). Consistent with previous findings (e.g. Amirkhan, 1990; Bijttebier \& 
Vertommen, 1997) the strongest correlation was between the Problem Solving and Social Support Seeking scales $(r=.49)$. Intercorrelations between the three subscales were appreciably higher than results reported elsewhere (e.g. Amirkhan, 1990; Ptacek et al., 1994). This may be because the participants in this study had time to evolve coping strategies that interact in a complementary way as a consequence of the chronicity of the challenge to health posed by amputation. However, this may also be a characteristic of an older sample per se, and given the average age of our participants (72 years), such a possibility should be explored further for its adaptive value. The internal consistencies of the Avoidance, Social Support Seeking and Problem Solving subscales compare favourably with results reported elsewhere (e.g. Ager \& MacLachlan, 1998; Bijttebier \& Vertommen, 1997; Clark et al., 1995).

In conclusion, the current analyses demonstrate the replicability of the CSI factor structure and indicate satisfactory performance in terms of internal reliability. Thus findings from the current research provide empirical support for the models proposed by Amirkhan (1990) and Ager and MacLachlan (1998) and are consistent with the suggestion that the scale is generalizable across population, cultural, and situational variation. Both the original factor structure of the CSI, derived from a sample of young healthy male and female Californians, and the four-dimensional structure, derived in a sample of Malawian undergraduate students, extend to the current sample of elderly male British war veterans, with a chronic physical health problem which presents a broad range of psychosocial challenges (Gallagher \& MacLachlan, 2000). This extension of the CSI is of value to our increasingly elderly population, especially those who live with chronic health problems.

\section{Acknowledgements}

We gratefully acknowledge funding for this research from the Irish Research Council for the Humanities and Social Sciences, and the British Limbless Ex-Service Men's Association, as well as the time and care taken by individual members of BLESMA in responding to our survey.

\section{References}

Ager, A., \& MacLachlan, M. (1998). Psychometric properties of the Coping Strategy Indicator (CSI) in a study of coping behaviour amongst Malawian students. Psychology and Health, 13, 399-409.

Amirkhan, J. H. (1990). A factor analytically derived measure of coping: The Coping Strategy Indicator. Journal of Personality and Social Psychology, 59(5), 1066-1074.

Bentler, P. M. (1988). Comparative fit indexes in structural models. Psychological Bulletin, 107, $238-246$.

Bijttebier, P., \& Vertommen, H. (1997). Psychometric properties of the Coping Strategy Indicator in a Flemish sample. Personality and Individual Differences, 23(1), 157-160.

Bijttebier, P., \& Vertommen, H. (1999). Coping strategies in relation to personality disorders. Personality and Individual Differences, 26(5), 847-856.

Billings, A. G., \& Moos, R. H. (1984). Coping, stress and social resources among adults with unipolar depression. Journal of Personality and Social Psychology, 46, 877-891.

Bollen, K. A., \& Long, J. S. (Eds.). (1993). Testing structural equation models. London: Sage Publications, Inc.

Browne, M. W., \& Cudeck, R. (1989). Single sample cross-validation indices for covariance structures. Multivariate Behavioral Research, 24(4), 445-455. 
Carver, C. S., Scheier, M. F., \& Kumari Weintraub, J. (1989). Assessing coping strategies: a theoretically based approach. Journal of Personality and Social Psychology, 56(2), 267-283.

Clark, K. K., Bormann, C. A., Cropanzano, R. A., \& James, K. (1995). Validation evidence for three measures of coping. Journal of Personality Assessment, 65(3), 434-455.

Endler, N. S., Corace, K. M., Summerfeldt, L. J., Johnson, J. M., \& Rothbart, P. (2003). Coping with chronic pain. Personality and Individual Differences, 34(2), 323-346.

Endler, N. S., \& Parker, J. D. A. (1990). Coping Inventory for Stressful Situations (CISS): Manual. Toronto.

Folkman, S., \& Lazarus, L. (1985). If it changes it must be a process: a study of emotion and coping during three stages of a college examination. Journal of Personality and Social Psychology, 48, 150-170.

Folkman, S., \& Lazarus, R. S. (1980). An analysis of coping in an adequately functioning middle-aged community sample. Journal of Health and Social Behavior, 21, 219-239.

Gallagher, P., \& MacLachlan, M. (1999). Psychological adjustment and coping in adults with prosthetic limbs. Behavioral Medicine, 25(3), 117-124.

Gallagher, P., \& MacLachlan, M. (2000). Development and psychometric evaluation of the Trinity Amputation and Prosthesis Experience Scales (TAPES). Rehabilitation Psychology, 15, 130-154.

Gillespie, A., Peltzer, K., \& MacLachlan, M. (2000). Returning refugees: psychosocial problems and mediators of mental health among Malawian returnees. Journal of Mental Health (UK), 9(2), 165-178.

Glennon, S., \& MacLachlan, M. (2000). Stress, coping and acculturation of international medical students in Ireland. In M. MacLachlan \& M. O'Connell (Eds.), Cultivating pluralism: Psychological, social and cultural perspectives on a changing Ireland (pp. 259-277). Oak Tree Press.

Haan, N. (1982). The assessment of coping, defence and stress. In L. Goldberg \& S. Breznitz (Eds.), Handbook of stress: theoretical and clinical aspects (pp. 254-269). New York: The Free Press.

Hu, L.-T., \& Bentler, P. M. (1998). Fit indices in covariance structure modeling: sensitivity to underparameterized model misspecification. Psychological Methods, 3(4), 424-453.

Hu, L.-T., \& Bentler, P. M. (1999). Cutoff criteria for fit indexes in covariance structure analysis: conventional criteria versus new alternatives. Structural Equation Modeling, 6(1), 1-55.

Joreskog, K., \& Sorbom, D. (2004). LISREL 8.7. Scientific Software Inc.: Chicago.

Lazarus, R. S. (1991). Emotion and adaptation. London: Oxford University Press.

Lazarus, R. S., \& Folkman, S. (1984). Stress, appraisal and coping. New York: Springer.

Livneh, H., Antonak, R. F., \& Gerhardt, J. (1999). Psychosocial adaptation to amputation: the role of sociodemographic variables, disability related factors and coping strategies. International Journal of Rehabilitation Research, 22(1), 21-31.

Livneh, H., Antonak, R. F., \& Gerhardt, J. (2000). Multidimensional investigation of the structure of coping among people with amputations. Psychosomatics, 41(3), 235-244.

Lyne, K., \& Roger, D. (2000). A psychometric re-assessment of the COPE questionnaire. Personality and Individual Differences, 29(2), 321-335.

MacCallum, R. (1995). Model specification: procedures, strategies, and related issues. In R. H. Hoyle (Ed.), Structural equation modeling: Concepts, issues, and applications. Thousand Oaks, CA: Sage.

Mikulincer, M., \& Florian, V. (1996). Coping and adaptation to trauma and loss. In M. Zeidner \& N. S. Endler (Eds.), Handbook of coping: Theory, research and applications (pp. 554-572). New York: John Wiley and Sons Inc.

Parker, J. D. A., \& Endler, N. S. (1992). Coping with coping assessment: a critical review. European Journal of Personality, 6, 321-344.

Ptacek, J. T., Smith, R. E., Espe, K., \& Raffety, B. (1994). Limited correspondence between daily coping reports and retrospective coping recall. Psychological Assessment, 6(1), 41-44.

Satorra, A., \& Bentler, P. M. (1988). Scaling corrections for statistics in covariance structure analysis. Los Angeles: University of California.

Schumacker, R. E., \& Lomax, R. G. (1996). A beginner's guide to structural equation modeling. Mahwah, New Jersey: Lawrence Erlbaum Associates Inc.

Schwarzer, R., \& Schwarzer, C. (1996). A critical survey of coping instruments. In M. Zeidner \& N. S. Endler (Eds.), Handbook of coping: Theory research applications. Oxford, England: John Wiley \& Sons. 
Spangenberg, J. J., \& Theron, J. C. (1999). Stress and coping strategies in spouses of depressed patients. The Journal of Psychology, 133(3), 253-262.

Stevens, J. P. (2002). Applied multivariate statistics for the social sciences (fourth ed.). New Jersey: Lawrence Erlbaum Associates, Inc.

Utsey, S. O., Ponterotto, J. G., Reynolds, A. L., \& Cancelli, A. A. (2000). Racism and discrimination, coping, life satisfaction, and self-esteem among African Americans. Journal of Counseling and Development, 78(1), 72-80.

Welch, J. L., \& Austin, J. K. (2001). Stressors coping and depression in haemodialysis patients. Journal of Advanced Nursing, 33(2), 200-207. 